\title{
Anchorage loss and distal teeth movement
}

Neam F Agha

BDS, MSc (Lect)

\author{
Dept of Pedod, Orthod and Prev Dent \\ College of Dentistry, University of Mosul
}

\begin{abstract}
Aim: To develop the amount of canine retraction or space closure and the amount of mesial migration of anchorage. Materials and Methods: Data collected from treated patients attending College of Dentistry/ Mosul University and from private clinics, in which a standardized method used for treatment work. Sixty eight patients, 37 have Class I crowding and 31 have Class II malocclusion were divided into two groups: Growing and non-growing patients. The data subjected to statistical analysis for description of variables. Results: There were what we can call them "primary factors" affecting anchorage loss which is represented by the type of malocclusion. In Class II malocclusion, greater anchorage loss than Class I crowding, and in the "secondary factors" effect of patients age, higher anchorage loss in growing subjects than non-growing patients was found. Conclusion: The type of malocclusion is important in affecting anchorage loss which is considered a primary factor. Also, higher anchorage loss in growing patients than non-growing patients was found.

Key Words: Anchorage loss, canine retraction.

Agha NF. Anchorage loss and distal teeth movement. Al-Rafidain Dent J. 2006; 6(1): 78-83.

Received: $14 / 8 / 2005 \quad$ Sent to Referees: $12 / 9 / 2005$

Accepted for Publication: 21/11/2005
\end{abstract}

\section{INTRODUCTION}

Anchorage is the resistance to unwanted tooth movement and is commonly described as the desired reaction of posterior teeth to space closure mechanotherapy to achieve treatment goals; i.e., minimum, medium and maximum anchorage. ${ }^{(1-3)}$

Anchorage loss (AnLo) is a reciprocal reaction that could obstruct the success of orthodontic treatment by complicating the anterior-posterior correction of malocclusion and possibly detracting from facial esthetic.

Orthodontic tooth movements are based on the ability of bone to react to mechanical stresses with the apposition and resorption of alveolar bone. Currently, the underlying biophysical, biochemical and cellular processes are subjects of numerous studies. At present, however, an analytical description of tooth movements including all components of the processes involved seems to be impossible. ${ }^{(4)}$

The concept of a well-interdigitated occlusion acting to enhance molar anchorage is an accepted dogma. Greekmore ${ }^{(5)}$ found that the posterior teeth occupy onethird to one-half of extraction space in first and second premolar extraction, respectively.
The desire to minimize anchorage loss is of major concern because residual overjet, non cusp fossae relationships and deep bite are affected. Raboud and Faulkn$\mathrm{er}^{(6)}$ suggested that incorporation of the second molars in the anchorage strategy, low retraction forces and frictionless mechanics are superior to the conventional anchorage means such as head gear or non en masse retraction.

The rate of tooth movement during orthodontic treatment is dependent on a number of mechanical and biologic variables. The variables implicated in bracketwire friction include bracket material and quality of manufacture, slot size, wire alloy type, wire size, ligature material and force of ligation. Careful selection of appropriate brackets, wires and ligatures may be used to predictably control the relative rates of tooth movement and to enhance or reduce anchorage. ${ }^{(7)}$ This has clinical implications in cases demonstrating critical posterior anchorage, such as those requiring reduction of a large overjet. In such malocclusions, one would be wise to use a bracket and arch combination that minimizes friction so as to conserve the available anchorage. ${ }^{(8)}$

If an upper canine is to be retracted 
with bodily movement using fixed appliance, the force applied to the tooth will be approximately $100 \mathrm{~g}$. Forces in the opposite direction varying from $67 \mathrm{~g}$ on the first molar to $33 \mathrm{~g}$ on the second premolar resist this. Low level will produce negligible tooth movement and the effect of a light force of $100 \mathrm{~g}$ would be to retract the canine with minimal anterior unwanted movement of anchored teeth. However, if the force level is increased to $300 \mathrm{~g}$ the force level on the anchored teeth increased dramatically to the level where unwanted teeth movements will occur. ${ }^{(9)}$

Vasquez et al. ${ }^{(10)}$ and Daniel and Pollit $^{(11)}$ suggested several clinical principles that can be followed to enhance anchorage in adult patients:

1. Incorporating more teeth in the anchor unit, thus distributing the force over a greater root area.

2. Tying the anchor unit together more rigidly.

3. Varying the moment-to-force ratio so that the active unit is tipped while the anchor unit is translated.

4. Applying forces to the anchor unit that could be neutralized by occlusal forces.

Another way to vary the force levels between the active and anchor units is to vary the friction, since the force that acts at the root surface is the result of applied force minus the force lost due to friction.

In recent years, endosseous implants have been used as orthodontic anchorage. $^{(10,11)}$

The aims of the research were to develop the amount of canine retraction or extracted space closure and the amount of mesial migration of anchor teeth or AnLo. Also to know the contribution of age (growing versus non-growing patients) and types of malocclusion, Class I crowding to Class II malocclusion, to determine the relative factors on AnLo.

\section{MATERIALS AND METHODS}

The sample consisted of 68 patients treated in the Department of Pedodontics, Orthodontics and Preventive Dentistry, College of Dentistry, University of Mosul and from the private practices. The patients have either Class I occlusion with crow- ding. Those need extraction of first premolar to relieve the crowding were 37 ; or $\mathrm{Cl}$ ass I or II molar occlusion. Those patients have increase of overjet more than $5 \mathrm{~mm}$ and need reduction of the overjet by extraction of first premolar were 31 . The age of the patients varied form 12-25 years. A study cast was taken from the sample. Then it divided into two groups:

1. Growing Patients (G): The first group aged 12-18 years as determined by chronological and normal growth curves. ${ }^{(3)}$

2. Non-growing Patients (nG): The second group aged 19-25 years.

Regarding treatment method, all the patients treated with edge-wise fixed appliance using stainless steel $0.022 \times 0.028$ inch standard brackets and according to standardized moderate anchorage control regimen.

The regimen included extraction of two maxillary first premolars, the space closure by individual sliding of canine using round stainless steel wire 0.018 inch for initial retraction then converted to $0.016 \times 0.022$ inch rectangular wire to complete canine retraction, canine retraction by using elastic chain (Kunststoff transparent chain) changed every 3 weeks. Then, en mass incisors retraction using also $0.016 \times 0.022$ inch rectangular arch wire containing tear-drop loops activated $1 \mathrm{~mm}$ every 3 weeks. This regimen of activation produce initial force of 150 gm per side. ${ }^{(12,13)}$ The arch wire activated with tip back bend mesial to the first molars. After finishing and completion the space closure of the patient, another study cast was taken for each subject. So there were pre and post treatment study casts.

All the measurements were done on the pre (Figure 1) and post (Figure 2) treatment dental casts by using vernia. Those measurements were:

1. Distance of Canine (C): The length between tip of the canine to the buccal groove of the first molar. This selected in order to avoid the carious lesion that mainly occur in the occlusal surfaces. The difference of $\mathrm{C}$ distance between pre-treatment (C1) and post-treatment (C2) measurements record will give amount of canine retraction (distally movement of canine). 
2. Distance of Molar (M): Measured also from the buccal groove of first molar to the center of incisive papilla. This anatomical landmark was taken as a constant reference point that not affected by teeth movement (protraction or retracti-

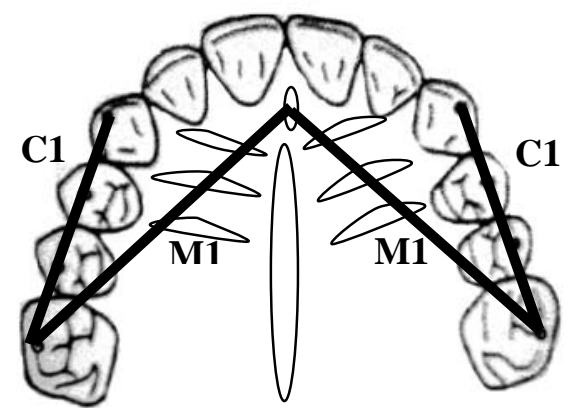

Figure (1): Pre-treatment measurements on). ${ }^{(14,15)}$ So, the difference between pre-treatment distance (M1) and posttreatment distance (M2) records will give the amount of AnLo, or mesial migration of first molar.

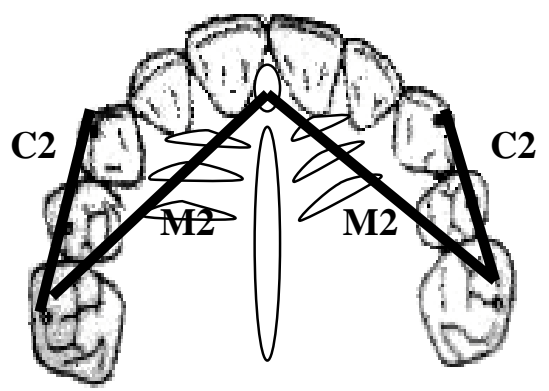

Figure (2): Post-treatment measurement

C: Canine distance, M: Molar distance

The data were analyzed by Minitab statistical program, including description of the variables (mean, standard deviation, minimum and maximum), and Student's ttest for comparison between different groups at $p \leq 0.05$ level.

\section{RESULTS}

The first analysis done was the comparison between right and left sides for each variable by using Student's t-test analysis. There was no significant difference between them at $p<0.05$. For $C$ distance, $p=0.75$ and 0.46 between two sides for pre and po- st treatment measurements, respectively. For $\mathrm{M}$ distance, $p=0.26$ and 0.79 for pre and post treatment measurements, respectively. For that reason, combined measurements of right and left for other analyses were taken.

Table (1) revealed the comparison between males and females according to age and type of malocclusion for $\mathrm{C}$ and $\mathrm{M}$ distances. The difference in the mean value for $\mathrm{C}$ and $\mathrm{M}$ distances was not significant for all the variables. That is why the effect of sex in the other analyses was excluded.

Table (1): Comparison between males and females according to age and type of malocclusion for canine and molar distances

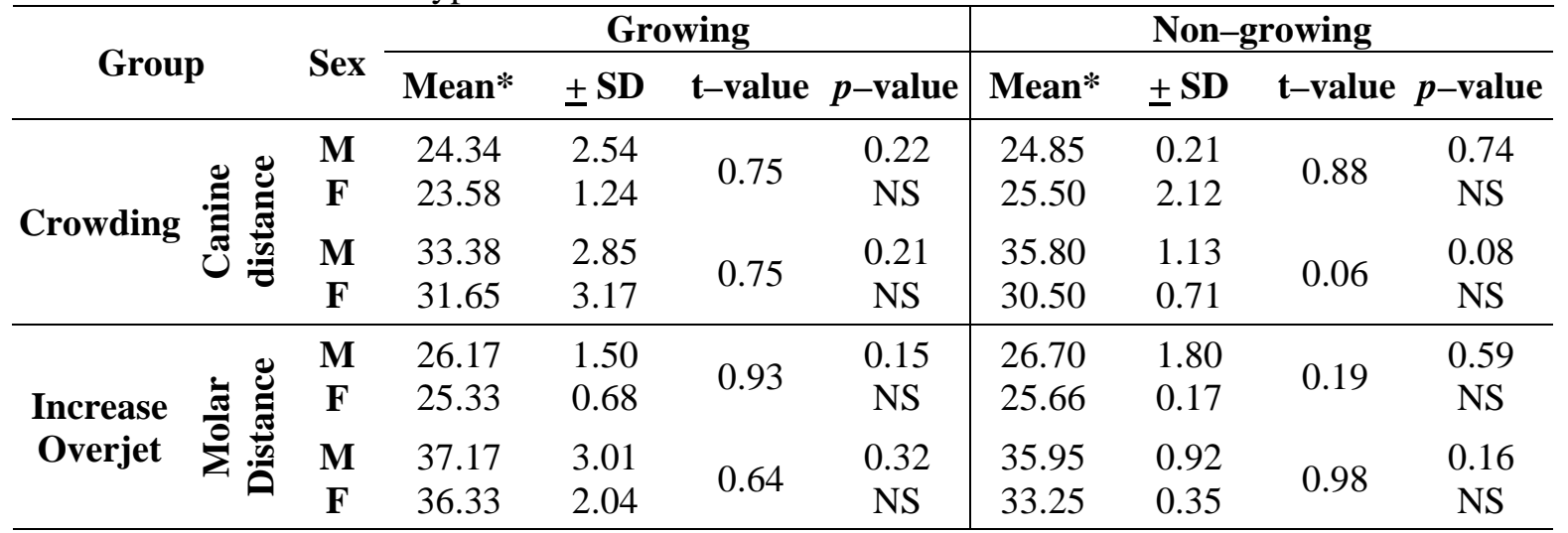

M: Male, F: Female, SD: Standard deviation, NS: Not significant.

*Measurements in millimeter. 
Table (2) showed the difference between pre and post treatment measurements for $\mathrm{C}$ and $\mathrm{M}$ distances. It could be noted that the mean value and minimum record was higher in Class II than for Class I crowding.
Table (3) revealed the comparison between $\mathrm{G}-\mathrm{nG}$ groups. In Class I crowding, it was seen that $\mathrm{G}$ group had higher mean value for both distances ( $C$ and $M$ ) than nG group, although the difference was not significant.

Table (2): Description of the difference pre-post treatment measurements for canine and molar distances

\begin{tabular}{cccccc}
\hline & Group & Mean* & 土SD & Minimum & Maximum \\
\hline Canine & Crowding & 6.74 & 1.57 & 2.3 & 10.0 \\
Distance & Increase Overjet & 8.14 & 1.33 & 6.0 & 19.3 \\
Molar & Crowding & 5.02 & 2.03 & 1.0 & 10.0 \\
Distance & Increase Overjet & 6.29 & 1.02 & 4.5 & 8.0 \\
\hline
\end{tabular}

SD: Standard deviation.

*Measurements in millimeter.

Table (3): Comparison between growing-non growing groups in Class I crowding

\begin{tabular}{cccccc}
\hline & Group & Mean* & \pm SD & t-value & $\boldsymbol{p}$-value \\
\hline Canine & Growing & 6.82 & 1.97 & \multirow{2}{*}{0.21} & 0.75 \\
Distance & Non-growing & 6.62 & 1.76 & & NS \\
Molar & Growing & 3.45 & 2.24 & \multirow{2}{*}{0.52} & 0.55 \\
Distance & Non-growing & 3.40 & 1.98 & & NS \\
\hline
\end{tabular}

SD: Standard deviation, NS: Not significant.

*Measurements in millimeter.

In Table (4), the comparison between G-nG groups in Class II malocclusion showed a higher mean value for $\mathrm{G}$ group for both distances than $\mathrm{nG}$ group, and the difference also was not significant.

Table (5) revealed the comparison between Class I-II malocclusion within $\mathrm{nG}$ group. It was demonstrated that in Class II, a higher mean value for both canine and $\mathrm{M}$ distances than in Class I crowding was noticed and the difference was significant.

Table (6) demonstrated the comparison between two malocclusions within $G$ group. It was also displayed higher mean value for Class II than for Class I. The difference in $\mathrm{M}$ distance which represents AnLo was significant, while for $\mathrm{C}$ distance, the difference was insignificant.

Table (4): Comparison between growing-non growing groups in Class II malocclusion

\begin{tabular}{cccccc}
\hline & Group & Mean* & \pm SD & t-value & $\boldsymbol{p}$-value \\
\hline Canine & Growing & 7.74 & 1.46 & \multirow{2}{*}{0.98} & 0.31 \\
Distance & Non-growing & 8.67 & 2.40 & & NS \\
Molar & Growing & 6.94 & 0.98 & \multirow{2}{*}{0.60} & 0.61 \\
Distance & Non-growing & 6.42 & 1.2 & & NS \\
\hline
\end{tabular}

SD: Standard deviation, NS: Not significant.

*Measurements in millimeter. 
Table (5): Comparison between Class I-II malocclusion within non-growing group

\begin{tabular}{cccccc}
\hline & Group & Mean* & \pm SD & t-value & $\boldsymbol{p}$-value \\
\hline Canine & Crowding & 6.62 & 1.57 & \multirow{2}{*}{2.01} & 0.01 \\
Distance & Increase Overjet & 8.67 & 1.33 & & $\mathrm{~S}$ \\
Molar & Crowding & 3.40 & 2.03 & \multirow{2}{*}{2.20} & 0.01 \\
Distance & Increase Overjet & 5.42 & 1.02 & & $\mathrm{~S}$ \\
\hline
\end{tabular}

SD: Standard deviation, S: Significant.

*Measurements in millimeter.

Table (6): Comparison between Class I-II malocclusion within growing group

\begin{tabular}{cccccc}
\hline & Group & Mean* $^{*}$ & \pm SD & t-value & $\boldsymbol{p}$-value \\
\hline Canine & Crowding & 6.82 & 1.94 & \multirow{2}{*}{1.00} & 0.27 \\
Distance & Increase Overjet & 7.74 & 1.90 & & NS \\
Molar & Crowding & 3.45 & 1.78 & \multirow{2}{*}{3.09} & 0.00 \\
Distance & Increase Overjet & 6.94 & 0.98 & & S \\
\hline
\end{tabular}

SD: Standard deviation, NS: Not significant, S: Significant.

*Measurements in millimeter.

\section{DISCUSSION}

Interest in characterizing the nature of the relation between the rate of orthodontic tooth movement and the extent of anchorage loss began in 1950 and 1960. In the last two decades, a growing interest became manifest for the view that orthodontic tooth movement should be considered as the result of biological relation to externally applied stimuli. $^{(16,17)}$

The age of the patient considered as important factor in orthodontic treatment. This factor involved in determining the rate of subsequent tooth movement and in the periodontal ligament may be responsible for the variation.

In this research, and in Class I crowding and Class II malocclusion, the $\mathrm{G}$ group have larger mean value for canine distance (amount of canine retraction), and for $\mathrm{M}$ distance (AnLo) than $\mathrm{nG}$ group. This finding supported the statement above and it was in agreement with other studies, ${ }^{(18,19)}$ which stated that one of the major factors is the character of the bone through which the teeth are being moved. Since the movement of teeth requires the cellular changes of the supporting bone and individual differences in bone density, metabolism and turnover which may be related to younger age than adults, might lead to the pos- sibility of individual strategies in clinical orthodontic therapy, although the difference in this research between $\mathrm{G}-\mathrm{nG}$ groups was not significant. The AnLo in $\mathrm{G}$ group was 3.45 and 6.94 for Classes I and II, respectively. In $\mathrm{nG}$ group, it was 3.40 and 6.42 for Classes I and II, respectively. The age factor is considered to be secondary factor in affecting AnLo during orthodontic therapy. This also supported by Gerons et $a .^{(3)}$

The same finding was reported by Harris et al. ${ }^{(20)}$ They found also G patient had greater AnLo ( $2.52 \mathrm{~mm}$ ) than $\mathrm{nG}$ patient $(0.2 \mathrm{~mm})$.

Class II malocclusion have larger mean value for all variables than Class I crowding, indifferent to age group ( $\mathrm{G}-\mathrm{nG})$. So, greater AnLo occur in treatment of Class II than for Class I malocclusion. This may be due to the amount of arch length deficiency.

Maxillary arch length discrepancy could be either crowding only or increase in the overjet, according to biomechanical principles. Less anchorage is required to relieve crowding than to reduce overjet; this approved by this research. So, the greater the crowding the lower the AnLo. This contradict the thought that the more arch length deficiency the greater the anchorage 
required. ${ }^{(1,2)}$

Gerons et al. ${ }^{(3)}$ and Ong and Woo$\mathrm{ds}^{(21)}$ supported the interpretation of the present research because on account of less crowding they reported greater AnLo. While Hart et al. ${ }^{(9)}$ have been reported to reduce AnLo by $0.6-0.7 \mathrm{~mm}$ on use differential moments. When maximum anchorage is required, AnLo was greater in Class I (0.6 $\mathrm{mm})$ than in Class II (0.28 mm) malocclusion.

\section{CONCLUSION}

The AnLo is a multifactorial response in relation to age, crowding and increase in overjet. The type of malocclusion is important in affecting AnLo. There was higher record of AnLo in Class II malocclusion than in Class I crowding and the difference was significant. Also, for the age group, $G$ patients showed larger AnLo than nG patients but the difference was not significant.

\section{REFERENCES}

1.Graber TM. Orthodontics: Current Principles and Techniques. $3^{\text {rd }}$ ed. CV Mosby Co. St Louis. 2000; Pp: 565-640.

2.Proffit WR. Contemporary Orthodontics. $3^{\text {rd }}$ ed. CV Mosby Co. St Louis. 2000; Pp: 295-362.

3.Gerons S, Shpack N, Kandos S, Davidovich M, Vardimon L. Anchorage loss: A multifactorial response. Angle Orthod. 2003; 73(6): 730-737.

4.Bourauel C, Kob D, Jagar A, Vollmer D. Simulation of orthodontic tooth movements. A comparison of numerical models. $J$ Orofac Orthop. 1999; 60(2): 136-151.

5.Greekmore TD. Where teeth should be positioned in the face and jaw and how to get them? J Clin Orthod. 1997; 31: 586-608.

6.Raboud DW, Faulkner MG. Three dimensional effects in retraction appliance design. Am J Orthod Dentofac Orthop. 1997; 112: 378-392.

7.Vaughan D, Nanda R, Currier B. Kinetic frictional forces between brackets and wires. Am J Orthod Dentofac Orthop. 1995; 108: 20-27.

8.Tselepis B, West C. Frictional resistance between brackets and arch wires. Am J Orthod Dentofac Orthop. 1994; 106: 131138.
9.Hart A, Taft L, Greenberg SN. The effectiveness of differential moments in establishing and maintaining anchorage. Am J Orthod Dentofac Orthop. 1992; 102: 434442.

10.Vasquez M, Calamo E, Becerra F, Ossa J, Enriquez C, Fresneda E. Initial stress differences between sliding and sectional mechanics with an endosseous implant as anchorage. Angle Orthod. 2001; 71(4): 247256.

11.Daniel JJ, Pollit M. Technique to reduce arch wire binding. Am J Orthod Dentofac Orthop. 1996; 110: 150-153.

12.Robest H, Sandy J. Anchorage control and distal movement. Br Dent J. 2004; 196: 255-263.

13.Ren Y, Maltha JC, Van H, Kuijpers AM. Optimum force magnitude for orthodontic tooth movement: A mathematical model. Am J Orthod Dentofac Orthop. 2004; 125(1): 71-79.

14.Haruki T, Little RM. Early versus late treatment of crowded first premolar extraction cases. Angle Orthod. 1998; 68: 61-68.

15.Hoggan BR, Sadowsky C. The use of the palatal rugae for assessment of antero-posteior tooth movement. Am J Orthod Dentofac Orthop. 2002; 121: 482-488.

16.Ren Y, Maltha JC, Anne MH. Optimum force magnitude for orthodontic tooth moment: A review of literature. Angle Orthod. 2002; 72(1): 86-92.

17.Dixon V, Read MJF, Brien KDO, Mandall NA. A randomized clinical trial to comp pare three methods of orthodontic space closure. Br J Orthod. 1994; 29(1): 31-36.

18.Andrew L, Sonis D. Comparison of Niti coil spring vs elastics in canine retraction. Am J Orthod Dentofac Orthop. 1994; 105: 293-285.

19.Jack JGM, Pilon A. Magnitude of orthodontic forces and rate of bodily tooth movement. Am J Orthod Dentofac Orthop. 1996; 109: 16-23.

20.Harris EF, Dyer GS, Vardimon JL. Age effects on orthodontic treatments, skeleton and dental assessment. Am J Orthod Dentofac Orthop. 1991; 100: 531-536.

21. Ong HB, Woods MG. An occlusal and cephalometric analysis of maxillary first and second premolar extraction effects. Angle Orthod. 2001; 71: 90-102. 